\title{
A Review of a Biomimicry Swimming Robot using Smart Actuator
}

\author{
Muhammad Shafique Ashroff Md Nor ${ }^{1}$, Mohd Aliff ${ }^{2} *$ \\ Malaysian Institute of Industrial Technology \\ Universiti Kuala Lumpur \\ Malaysia
}

\author{
Nor Samsiah ${ }^{3}$ \\ Center for Artificial Intelligence Technology (CAIT) \\ Faculty of Information Science and Technology \\ Universiti Kebangsaan Malaysia, Selangor, Malaysia
}

\begin{abstract}
Biomimicry-based robotic mobility is a newer subgenre of bio-inspired design and it's all about applying natural concepts to the development of real-world engineered systems. Previously, researchers used actuators such as motors, pumps, and intelligent materials or intelligent actuators to build many biomimicry robots. Due to the field's growing interest, this study will examine the performance of several biomimicry robots that have been built based on their different design, the type of material the robot utilizes, and the type of propulsion for the robot to swim while providing huge thrust. Robots must not only design such an animal, but its maneuverability and control tactics must also be tied to wildlife to provide the finest impersonation of biological life. Fish propulsion can be separated into two categories which are body and/or caudal fins (BCF) and median and/or paired fins (MPF). The old propeller system in underwater robot usually uses motor and pump. Many researchers have begun developing smart materials as drivers in recent years that can be grouped into four categories: shape memory alloy SMA, ionic polymer metal composite IPMC, lead zirconate titanate (PZT) and pneumatic soft actuator as replacement for pump or motor. Varied materials produce different result and can be applied for different propulsion modes. Future researchers working on biomimetic fish robots will be guided by the findings of this study.
\end{abstract}

Keywords-Biomimicry; fish propulsion; biological life; smart actuator

\section{INTRODUCTION}

Water covers 71 percent of the earth's surface, providing mankind with resources such as oil, food, and other necessities. Many engineers and biologists have worked to build new tools, machinery, and vehicles for underwater jobs like installing and maintaining cables and pipes, drilling for oil and gas on the seabed, and exploring the ocean floor for military and rescue missions. As a result, there has been a rise in demand for underwater robotics and vehicles [1]. However, today's underwater vehicles still have issues such as power conservation, mobility, limited thrust, and a design that is not ideal for usage in deep seas with high pressure. [1],[2]. However, there is always room for improvement for technologies and sciences. One of the methods is biomimetic approach which compares biological life as reference for the improvement. Biomimicry or biomimetic can be defined as a study of biological life such as animal and plant which will be implemented to science and technology.
Fish like robot that mimic biological life has gaining popularity in science and technology field. Fish exist in a wide range of shapes, sizes, and movement rates, which are influenced by several characteristics including dynamic shape and functional fins [3],[4]. Varied fish species have different advantages and drawbacks based on a variety of characteristics including shape, propulsion mechanism, and environment. All these specialties cannot be combined into a single robot system. The robot system, on the other hand, may always be improved. As a result, the goal of this work is to look at prior research on robots with fish-like characteristics to improve robot design and propulsion methods.

Current underwater vehicle can come out with result needed but more advance technology still needed since the result still limited. For example, in incident relate to Indonesia submarine crash in April 2021, underwater robot can help the exploration become faster rather than going in with another submarine for exploration and rescuing which may lead to the same incident happen. Some depth of the sea also cannot yet be explored by human due to pressure and dark surrounding. With robot this dream can be achieved with probability of success to increase, and risk can be reduced especially with robot that have underwater nature.

To create or build the best mimicry of biological life, the robot must not only act like the animal, but the shape design and control strategy also must relate to the wildlife. There are still significant challenges need to address to achieve good result. Algorithm to optimize control also needs to focus by the research community since this play's enormous potential in biomimicry robot. The choice of swimming style whether BCF or MPF and its modes are also important to choose based on the robot practical to maximize performance. BCF and MPF propulsion modes will be discuss later in another chapter.

Materials use to build the robot also must be considered since error in design can affect directly to performance of the robot. This has been proved in paper L. Neely et al. [5]. Same goes with the materials selection for actuator since this the most important part that will be used as propulsion system, and it will define whether the robot can act like subject animal or not. Lastly, dynamic modelling or the shape design of the fish needs to focus more to ensure robot not only can work on test bench but also the real underwater like deep sea or stream river.

*Corresponding Author. 
Underwater robot can consider robot that perform underwater operates without pilot or in another word works automatically. The idea initially started during late nineties by the marines. However, the development of underwater robot started way long before during 1950s where Dimitri Rebikoffin created first underwater robot called POODLE which later around 1970 more technology came used to gather and transfer data [6]. This technology test keeps increasing where during 1980 to 1990 many robots were built and evaluate to perform more specific task.

Many firms attempted to design and build robots to accomplish certain duties in the year 2000, but the robots produced still had many flaws, and their ability to maneuver in water was limited. Furthermore, corporations must invest a significant amount of money to construct these robots. However, in recent years, a growing number of scientists and research organizations have begun to investigate and construct robots made of less expensive materials. This version can lower the amount of money needed to manufacture a single robot while also meeting the demand for robots that can execute jobs in the water while moving faster.

Later, several scientists and researchers began investigating how to make robots by emulating the way fish swim in water. Various challenges faced by researchers at the time were handled by replicating the style of fish swimming in water, particularly those relating to the thrust for swimming robots and the dynamic design for underwater robots. Furthermore, smart actuators have been designed to replace traditional pumps and motors, allowing robots to swim and move in the water faster while using less energy. However, much more study and development are required before underwater robots can achieve the same level of capacity as fish that can swim more flexibly and steadily. The smart actuator will be explored later in this paper to better grasp the notion or operating principle, as well as other investigations carried out by other researchers in order to create this biomimetic robot.

\section{UNDERWATER ROBOT TECHNOLOGY DEMAND}

Although several have been constructed, autonomous underwater robot technology is still in the experimental stage. Proper navigation and propulsion, together with the suitable means to execute a task, are the keys to the best underwater technology [7],[43],[44]. The three main characteristic that limit the development are the compactness of the robot, flexibility, and the multifunction capabilities in single robot [8],[30],[60]. In oil and gas industry alone, this technology is critical as it can improve many outcomes. There are many depths of sea beyond reach of the current technology and dangerous for human to dive. With the usage of remote technology underwater robot, the job of diving and exploration will increase the effectiveness and at the same time eliminating danger or incident that might occur.

The demand on the exploration of the underwater increases the demands of the robot technology. This exploration can cover much as sea mapping, sea monitoring and deep-water oil search. Unmanned with the advance smart sensor will help the sea exploration. Technically, underwater robot demand can be divided into four main categories which are commercial mission, oceanographic research mission, military mission, and engineering research [9, 10],[62]. The main major factor for underwater robot grows demand is exploration of mineral since of the sea mineral is still vast with most part of it still not be explored by researcher.

Commercial mission is usually being developed by multiple industry related to deep water especially oil and gas company. This robot task covers underwater survey, inspection, and repair, welding cutting, collecting sample and object recovery at the offshore. Since oil and gas industry work with deep sea, this technology is important to them specially to reduce risk and loss. For example, people who are related to this industry do not have to go and dive deep sea to look and find the oil under the sea. By sending robot, it can find and look for the oil and at the same time can collect the sample.

Meanwhile, oceanographic research mission helps to monitor index level of health in maritime life and environment. It also helps to search and discover new species and deep-sea exploration. Scientist or marine's scientist also use demanding robot for sea exploration to increase their input such as exploration for sea mapping [29]. Technically, only less than $20 \%$ of sea has been explored and the rest remain mystery to the world and science. Explorer cannot just send submarine to explore this part of deep sea because it not only costs a lot of money but the submarine itself needs human to operate which is dangerous and life of this explorer at stake. To do this, scientist really needs smart robot to this for them.

Military also demand underwater technology to defend especially country that surrounded by sea. The military mission also includes rescue mission in deep sea incident such as when Indonesia submarine collapsed in 2021. The rescue and retrieve mission took a lot of time and military technology from various countries due to rough sea condition. military demand also related to intelligence, surveillance, inspection, underwater repair and maintenance navigation and communication. It is believed that more advance and smart technology will help this mission to work better and faster if this incident happens again in the future.

For engineering research, the current design robot will be improved, and the current design will be used as the sample. This process includes the improvement of navigation, propulsion, and control system. This will help the future design and product to work better as compared to current robot. Data from this research later will be significant for the future robot and researcher to produce better technology.

Some robots also can be use as other purpose for example sea cleaning and fisherman work related. This may not improve the quality of the job but may reduce the risk on wildlife itself. As per For Market report on 25th February 2020, global underwater robotics market demand expected reach up to 7.08 billion US Dollar by 2025. This show that underwater robot demand is big and needed by many industries.

\section{FISH SWIMMING PROPULSION}

Fish swimming propulsion can be divided into two categories which are body and/or caudal fins (BCF) and median and/or paired fins (MPF) [10,23,31]. Almost $85 \%$ of fish use BCF locomotion modes to swim while the rest $15 \%$ 
use MPF modes [1,2,10]. BCF locomotion fish uses its body to produce propulsive force opposing its direction force to provide forward swimming movement and MPF use it median or paired fins to produce propulsive force. Swimming in BCF mode is faster than swimming in MPF mode, however MPF variants are more maneuverable than BCF modes [11]. For the movement characteristic of swimming fish, it is divided into two categories which are undulation and oscillation. Undulation is process of fish body propeller to provide waves along its propulsive structure while undulation is body part by swinging back and forth. This example can be seen from stingray (undulation) and manta ray (oscillation) [12,33]. To measure fish speed, scientist usually uses Body Length per second $(\mathrm{BL} / \mathrm{s})$, but some also still prefer centimeter per second $(\mathrm{cm} / \mathrm{s})$ or meter per second $(\mathrm{m} / \mathrm{s})$.

\section{A. Body and/or Caudal Fins (BCF)}

The modes of BCF propulsion are categorized into five groups. The modes are anguilliform, subcarangiform, carangiform, thunniform and ostraciiform [11,13,23]. BCF modes fish use undulation or oscillation throughout their body to produce thrust force. Fig. 1 shows the difference in the wavelength and the amplitude which later proportional with the thrust generated. From image, anguilliform has the highest degree of change in body change which entire body to generate thrust force compared to others. Example of this propulsion method can be seen on the eel. These modes can change the direction of the swim forward or backward by changing it body undulation. It has high maneuverability but lack in hydrodynamic which lead to more energy loss [32]. These modes have been practiced in robot lead Niu X. et al. by replicating movement to swim forward and backward like fish and succeed. Because it exploits the connection of small elements joined together to form a robot, this robot design uses a lot of servo motors compared to other designs. Other report also has been recorded to imply this method to robotic and based on their design it required up to twenty serial linked actuators as a propeller.

Subcarangifrom and carangiform use half and one-third of their body to produce thrust force. Although the movement of body anguilliform is higher compared to other, subcarangiform has higher speed but must compromise in term of their abilities to turn and accelerate due to inability to bend on their body. 3D simulation test suggests that robot that wanted to apply carangiform method should have flexible tail with multiple joint and right frequency to achieve appropriate speed and thrust [14],[15],[24].

Thunniform mode uses less than $30 \%$ of its body (fins are) participate in undulation to produce thrust force and the rest of the body remain stationary. Ostraciiform meanwhile purely uses oscillatory and can be categorized into both BCF and MPF based on use to flap. These two designs are hydrodynamically less efficient due to most of their body parts remain stationary.

\section{B. Median and/or Paired Fins (MPF)}

Just like BCF, MPF propulsion also divided into five modes which are rajiform, diodontiform, amiiform, gymnotiform and balistiform. MPF mostly used by fish in term of auxiliary propulsor and maneuvering as well as stabilization. It also provides acceptable thrust force as a locomotion at every low speed (3BL/s and below) [8]. MPF fish multiple small fins rays that are connected through flexible or soft membrane as medium to produce wave for propulsion. This due to fins capability of two-degree of freedom movement. Rajiform and diodontiform use undulation method to produce propulsive waves throughout large and flexible pectoral fins [47]. Rajiform modes can be seen mostly in manta, skates, and rays. Aminiiform also uses undulation, but usually only dorsal fins move and in many cases body axis is hold straight. Gymnotiform also same as aminiiform which body axis is held straight during swimming, but it uses long based anal fins. Balistiform can be seen mostly on balistidae family of fish. It uses both anal and dorsal fins to provide propulsive force as a locomotion. The overview of fins use in MPF propulsion can be seen in Fig. 2.

Scientists have also worked on MPF Style swimming robotic because MPF based fish has better role in linear motion, controllability table and maneuvering [16],[17]. Many from MPF design robots that include paired pectoral fin has shown good propulsive efficiency and maneuverability. A group of researchers from National University of Singapore has developed a manta robot that can swim up to $2 \mathrm{BL} / \mathrm{s}$ and can work up to 10 hours which show a significant result in biomimicry robot.

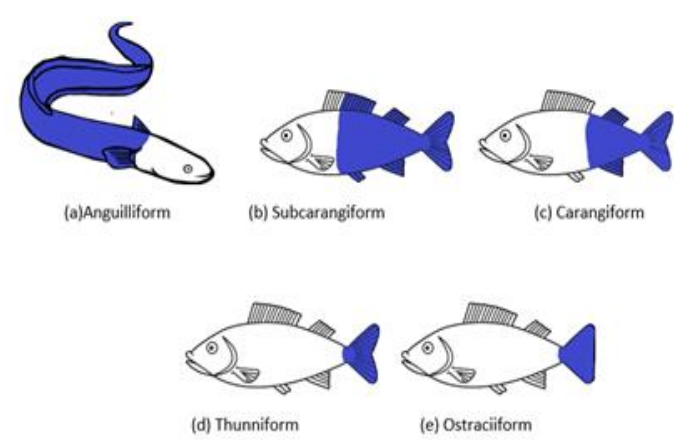

Fig. 1. Degree of Body Movement of BCF Fish. (a) Anguilliform (b) Subcarangiform (c) Carangiform (d) Thunniform (e) Ostraciiform. (Adapted and Redraw from P. Du Raisamy et al. [13]).

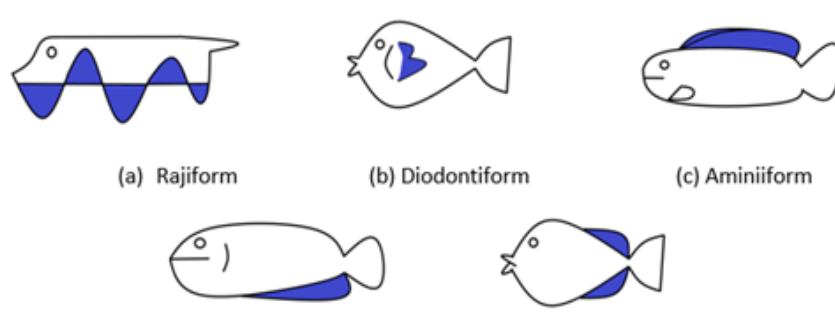

(d) Gymnotiform

(e) Balistiform

Fig. 2. Degree of Body Movement of BCF Fish. (a) Rajiform (b) Diodontiform (c) Aminiiform (d) Gymnotiform (e) Balistiform (Adapted and Redraw from P. Duraisamy et al. [13]). 


\section{SMART MATERIALS IN FISH PROPULSION ROBOT}

Authors To make a fish robot biomimicry body that can copy fish movement, the propeller or pump needs to be replaced. These materials are called smart actuators which can be classified into four categories which are shape memory alloy (SMA), ionic polymer metal composite IPMC, lead zirconate titanate (PZT) and pneumatic soft actuator [27]. Smart materials use continuously increasing due to capability of materials to meet the demand of the robot to become smaller and lighter in design [18].

SMA is a thermomechanical actuator due to its ability to change phase with the change of temperature of the materials. The capability of SMA to change shape by applying temperature variant make it valuable to use as smart materials [18],[45]. There are two types of SMA which are one way and two-way memory. One way memory will only be deformed or shrink when heat is applied while two-way has shape with high temperature and low temperature. At two-way, during room/low temperature, it will have one shape and at heated temperature it will have one shape. The different is one way needs to be heated first before it can back to normal temperature [13],[77]. Fig. 3 shows concept of the SMA material using SMA connected to spring [67]. Lower figure shows that during heated, the spring expended due to steel spring shrink compared to upper figure where steel spring is in normal condition when no heat applied.

IPMC made of three-layer materials which two are metal electrodes and single layer of thin electrode membrane. These three layers are arranged like sandwich which membrane in between the electrode. When voltage applied and create electric field, cation with water molecules will move toward cathode which will create imbalance. This will create more concentration on cathode and bend toward anode [19,37]. There are many different IPMC which usually differed based on chemical structure and properties such as Nafion, Flemion and other properties. However, IPMC usually made with Nafion is widely used [40,59].

PZT applied and piezoelectric effect which is the ability of certain materials to produce or generate electric charge upon the mechanical stress. When both surface of PZT is compressed by outside pressure, it will generate electric field propositional to external pressure.

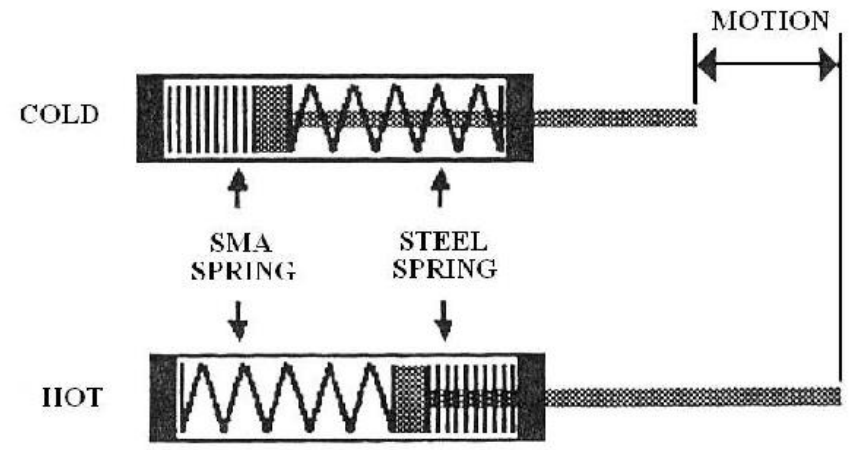

Fig. 3. SMA Actuation Sample (Adapted from Degeratu, S. et al [67]).

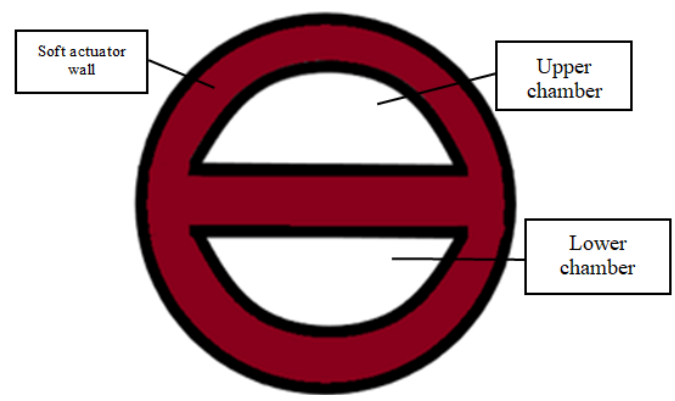

Fig. 4. Example Cross Section Design of Bending in Pneumatic Soft Actuator (Adapted and Redraw from K. Suzumori et al).

Pneumatic soft actuator is the newest technology that has been implemented to bio-mimicry robot. The working principle of pneumatic soft actuator is simple which consists of single or more chamber of rubber structure which is used with fiber or vice versa. This method is expected to be the most promising actuator in biomimicry robot due to its simple structure, high power/weight ratio, water resistance and high compliance [14]. Fig. 4 shows possible simple cross section for bending use in soft actuator. For example, when air is applied to bottom chamber, it will bend upward. By applying concept of bending up-down or front-back, it can be used for propulsion.

\section{BIOMIMETIC ROBOTS}

Several factors must be considered when developing a robotic fish propulsion system that incorporates intelligent materials, including the robot's dynamic shape, swimming pattern, and environment [46]. In brief, the actuator and swimming modes are listed according to the institution that developed the biomimetic underwater robot. John Finkbeiner et al. [34] design has two major components for the build which are fins and tail that use SMA. The fins are made up of five separate fins that are coupled together and respond to the fish robot's movement and direction. Fishtail fins are also used to assist robots swim more efficiently and steadily. In Fig. 5, center plate will act actuator for the SMA using which is attached to pulley that act like muscle. It uses as maneuvering system and at the same time produce flapling motion that help the robot swimming by moving the back part (tip) of body left and right. This swimming style can be seen in many fish.

SMA wires come in many sizes and produce different result. Selecting thicker wire will produce greater full force but will cause longer time for full actuation. To calculate force, drag on the robot can be calculate as Eq. (1). $\rho$ is the water density $\left(997.1\left(\mathrm{~kg} / \mathrm{m}^{3}\right), V\right.$ is the model velocity, $C_{d}$ is the flat plate perpendicular, and $A$ is the surface area of the fins.

$d=\left(\rho V 2 C_{d} A\right) / 2$

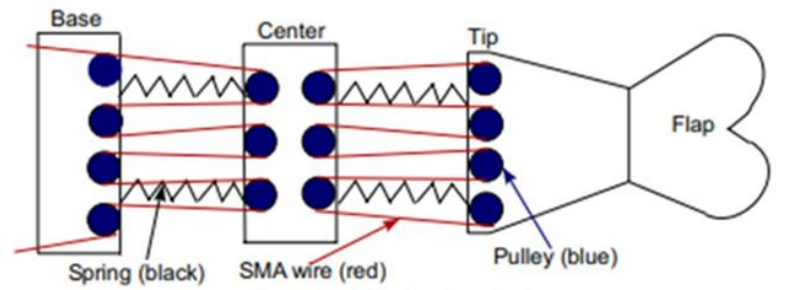

Fig. 5. Fish Tail (Adapted from J. Finkbeiner et al.). 
The design of manta ray by Zhenlong Wang et al. also uses SMA as a propulsive system. Two SMAs are attached to each side of ray's fin to provide flapping motion. Fig. 6 shows the structure of fins ray's design. These fins are connected to polyvinyl chloride (PVC) sheet to make a triangle shape that mimicking manta rays. When upper side of SMA applied an electric, it will bend upward and when applied to bottom part it will bend downward. The SMA wire no change when no electric applied since no thermo change (cool) [35,36]. Zhenlong Wang also has made a design based in subcarangiform modes making half of the back side of the body to use as a propulsive system. It uses two different parts where one part is active component and another one is passive component that react based on active component (biomimetic fins using SMA) $[25,26,38]$.

Fig. 7 shows the speed forward and turning swimming of robot by Zhenlong W. et al. Forward swimming achieve maximum frequency of $8.33 \mathrm{~Hz}$ with $25 \%$ duty ratio and 11.1 $\mathrm{Hz}$ for turning with $33.3 \%$ duty ratio. Duty ration means ratio of power on time of period over the periodic time. The longer power on time indicates the larger bending angle of the robot. The fastest swimming forward achieves at $2.1 \mathrm{~Hz}$ frequency with $16.7 \%$ duty ratio. Both $25 \%$ and $16.7 \%$ duty ratio of fish swimming speed decrease with the increase of frequency.

For turning radius, the result increase for both $33 \%$ and $25 \%$ duty ratio but start to decrease at certain frequency. The highest value come at $3.13 \mathrm{~Hz}$ with $25 \%$ duty ratio. Speed of turning achieve minimum turning radius at $136 \mathrm{~mm}$ at $3.7 \mathrm{~Hz}$ with $33 \%$ body ratio. The lower the speed of turning means faster time. All this result achieve from testing in tank and result may different if test outside or in water with flow.

Joel J. Hubbard et al. has designed a robot that uses both MPF and BCF propulsion. The project uses both pectoral fins mainly for maneuverability such lift, dive and turning while caudal fins mainly for propulsion. The robot takes advantage of IPMC with seven different surface that react differently for propulsion and maneuverability. Maximum speed for in initial test for propulsion on platform was $2.8 \mathrm{~cm} / \mathrm{s}$. The idea of using seven different surfaces for more flexibility and multiple degree of freedom can be applied for further research [20].

To test effect waveform on stingray surface velocity, J. Nowell et al. developed a stingray test platform that body mainly made of acrylic. The robot design is not aerodynamically good since it only shape of box. The mechanical drive for this robot uses servo that attach with node to produce waveform. Each side has 10 servos and nodes resulting total 20 servos and nodes. The speed of this design varies depending on frequency of the servo applied. This paper can be used as baseline to understand surface velocity of stingray for future researchers. Three factors during robot tuning that can affect the performance of fish robot are frequency, amplitude, and Mean Wave Number (MWN) [41].

Fig. 8 shows that relationship between the wave parameters and surface velocity. By changing parameters of frequency velocity and Mean Wave Number (MWN) produce different result on surface velocity of the robot. Fig. 8a shows that zero amplitude resulting zero velocity and increasing linearly with increase of amplitude. This prove that amplitude has great

impact on robot speed. Fig. 8b also shows almost same result with increase of frequency has effect on fish velocity. Meanwhile, MWN produce rocking result along the stingray as the MWN will determine how many cycles of waves along the robot fins.

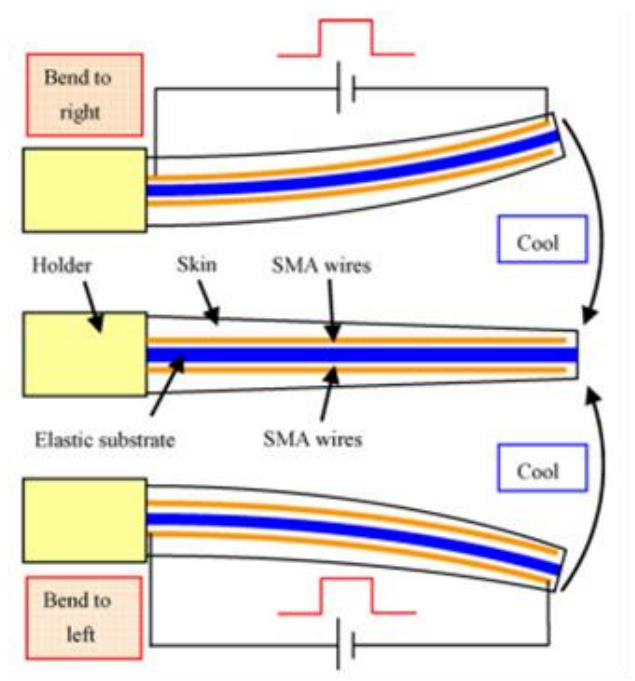

Fig. 6. Structure of Biomimetic Fin (Adapted from Z. Wang et al.).
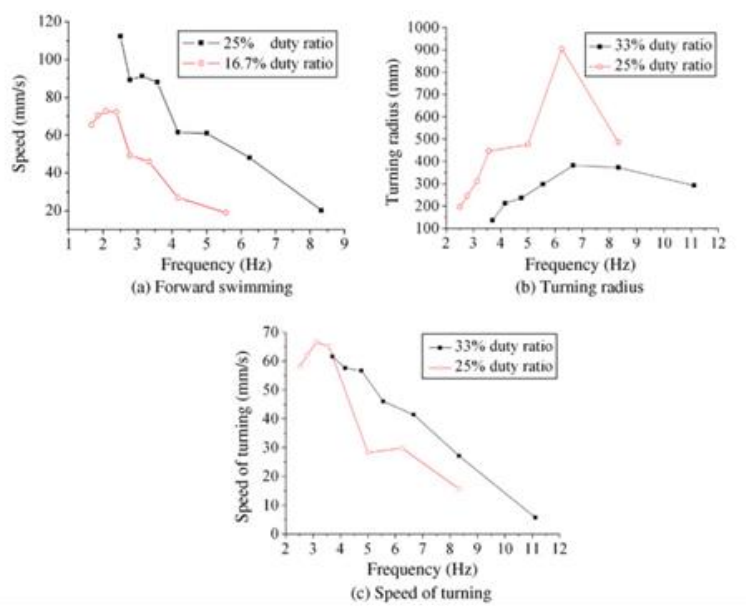

Fig. 7. The Micro-robot Fish's forward Swimming Speed, Turning Radius, and Turning Speed (Adapted from Zhenlong W. et al).

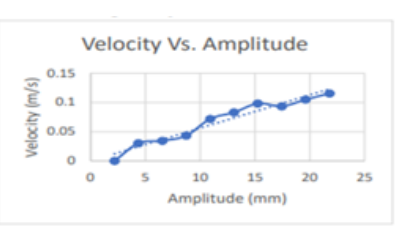

(a) Velocity vs Amplitude

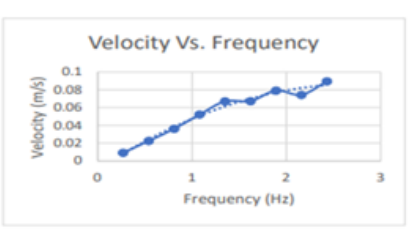

(b) velocity vs frequency

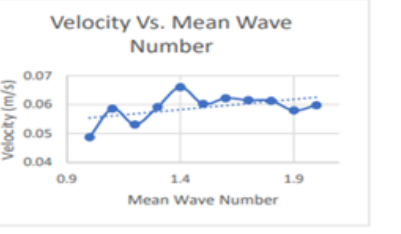

(c) Velocity Vs Mean Wave Number

Fig. 8. Test Result. (a) Velocity vs Amplitude. (b) Velocity vs Frequency (c) Velocity Vs Mean Wave Number (Adapted from Jordan N. et al.). 
The speed result compared to expected result based on mathematical result can be seen in Fig. 8. By applying 5V amplitude over different frequencies, the result was tested three times for each frequency to get average. Maximus speed was founded at frequency of $2 \mathrm{~Hz}$. The team assume the speed increase with the increase value of frequency as shown in Fig. 9 , but the result does not match due to low actuation of frequency will make larger tail actuation and resulting large yaw angle of the robot. The assumption only work frequency below the $2 \mathrm{~Hz}$ and start to decrease in speed when frequency is greater than 2 .

Manta ray robot using IPMC, and Polydimethylsiloxane (PDMS) membrane as shown in Fig. 10 was developed by team of University of Virginia which achieved $0.055 \mathrm{BL} / \mathrm{s}$ which is slower compared to robot that uses servo motor and SMA as a propeller. However, IPMC shows advantages with lighter design and less power consumption. Later, the writer also improves the design and achieve $0.067 \mathrm{BL} / \mathrm{s}$ in speed. To increase the efficiency, writer suggested two key points for the future which are dynamic of the manta robot and second is optimal design and of the fins [21,39].

Pneumatic soft actuator developed by K. Suzumori et al. [19] uses manta ray as sample for the fish. The design uses basic two degree of freedom in bending. The manta robot size is $17 \mathrm{~cm}$ width and $15 \mathrm{~cm}$ in length. The pneumatic tube is part one in each side of the robot and each tube in robot connected with two sources of pneumatic tube as source resulting four pneumatic tube to control the robot. The robot reaches speed of $10 \mathrm{~cm} / \mathrm{s}$. The simple robot design uses soft actuator which only rubber resulting the robot water resistance, simple structure, and light weight. The drawback here is robot must connect to pneumatic supply as power source for the fin undulation.

Design and preliminary evaluation by Lei Liu et al. conclude in their test that useful design of propulsion system with optimized phase control method can make a good MPF fish robot. The test subject reaches up to $0.8 \mathrm{BL} / \mathrm{s}$ in speed which is comparable to some BCF swimming robot. The robot suggests that by changing the frequency of servo, and phase shift and deflection angle of undulation fins will directly affect the swimming performance of the robot [42].

The testing considers three variable that may affect the robot swimming performance which are change in the phase of a waveform between adjacent fins ray $\left(\varphi_{0}\right)$, deflection angle between the fin's rays and the horizontal plane $\left(\varphi_{b}\right)$ and frequency of the robot. Fig. 11a shows that the speed of the robot increases linearly with frequency with $\varphi_{0}$ and $\varphi_{b}$ is $60^{\circ}$ and $0^{\circ}$, respectively. Fig. $11 \mathrm{~b}$ meanwhile shows that speed increase until certain degree of phase of a waveform between adjacent fins ray at max $60^{\circ}$ and start decrease in speed when the $\varphi_{0}$ increase. This due to theoretically that the swept area and the generating force undulating fins increase when phase of a waveform between adjacent fins ray decrease.

Tiefeng Lie et al. on paper title fastmoving soft electronic fish uses commercial silicone elastomer to as the body part [22]. The fabrication process takes few steps as shown in Fig. 12. Since the materials use here falls under categories soft actuator, the fins will flap as the voltage applied. The thrust force generates through periodic flapping pectorals and produce up to $135 \mathrm{~mm} / \mathrm{s}$ in speed for indoor and $64 \mathrm{~mm} / \mathrm{s}$ for outdoor.

Servo motor uses to control rod for stingray mimicry robot build group of researchers of Washington and Lee University a bit different from another robot since it uses flexible rod. This is due to aim of researchers to behave more like natural stingray skeletal structure. Same as other robot that uses servo motor, the speed of the robot depends on input parameter such as frequency to affect the swimming performance or speed. The robot can swim up to $6 \mathrm{~m}$ in straight line before it drifts from direction. This unintended drifting causes by the imbalance internal build and wing thickness (manufacturing error).

The result of swimming speed versus flapping frequency from this robot can be seen in Fig. 13. The robot swim fastest at $1.4 \mathrm{~Hz}$ flapping frequency by producing $13 \mathrm{~cm} / \mathrm{s}$ and $11.9 \mathrm{~cm} / \mathrm{s}$ or $0.37 \mathrm{bl} / \mathrm{s}$ or $0.34 \mathrm{bl} / \mathrm{s}$. the slowest is at $0.7 \mathrm{~Hz}$ which $4 \mathrm{~cm} / \mathrm{s}$ and $2 \mathrm{~cm} / \mathrm{s}$. interestingly, the sample fish for this robot design which is southern stingray swim with beat frequency of $1.744 \pm 0.42 \mathrm{~Hz}$ which is meeting the optimal value for the robot to swim at it best.

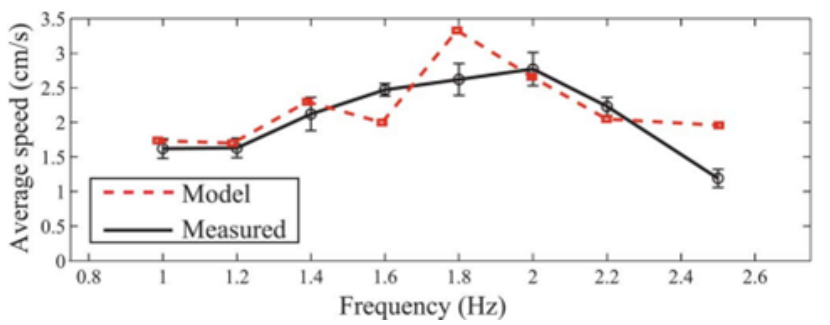

Fig. 9. When Operated by a 5-V Sinusoidal Voltage, the Experimentally Measured Swimming Speed of the Robotic System was Compared to the Model's Prediction. (Adapted from Joel J. Hubbard et al.).

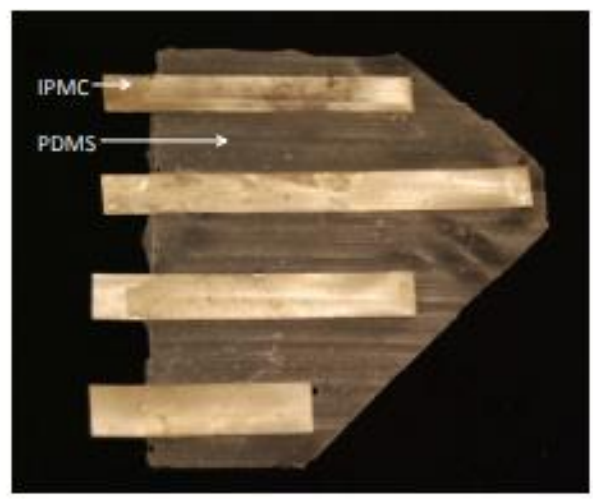

Fig. 10. IPMC/PDMS Artificial Pectoral Fins (Adapted from Z. Chen et al.).

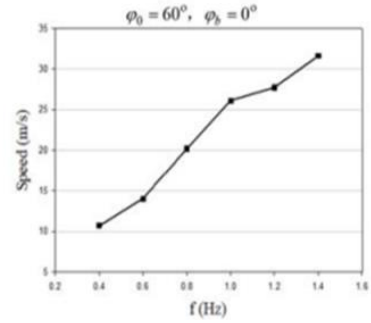

(a)

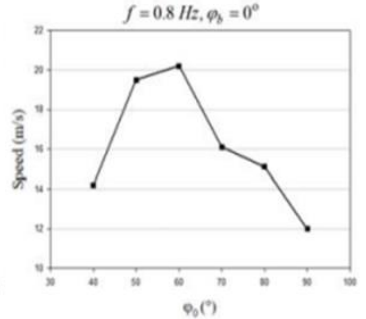

(b)
Fig. 11. Forward Motion Test (Adapted from Lei Liu et al.). 
A

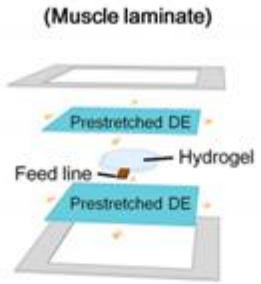

c

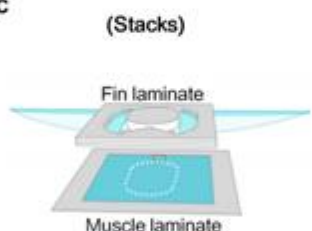

E

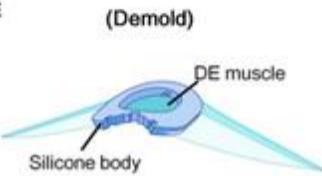

B
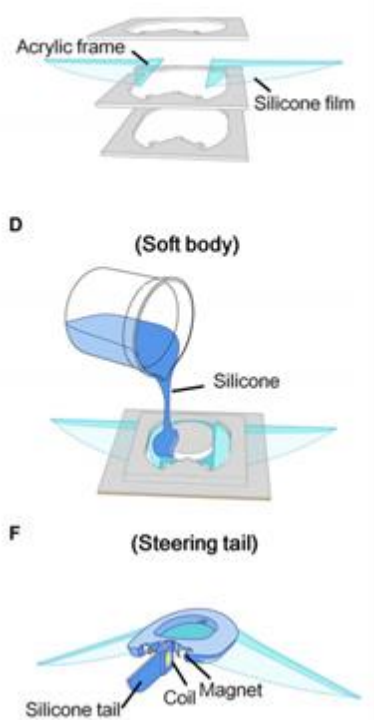

Fig. 12. Fabrication Process of Electro-ionic Fish (Adapted from T. Li et al.).

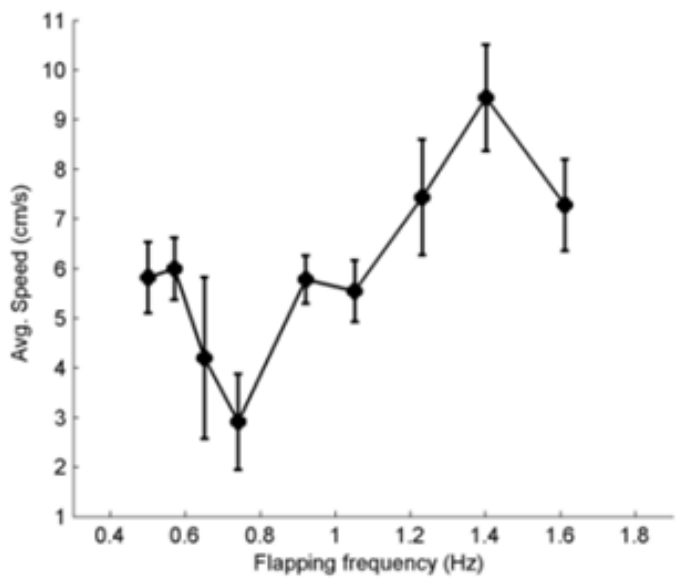

Fig. 13. Average Speed Versus Flapping Frequency (Adapted from Lincoln N. et al.).

Table 1 shows the summary and brief detail of the paper been discussed in this section. All project title, objective, project design and propulsion mechanism in this paper can be referred here.

TABLE I. SUMMARY OF PAPER DISCUSSED

\begin{tabular}{|c|c|c|c|}
\hline Title & Objective & Design & $\begin{array}{l}\text { Propulsion } \\
\text { Mechanism }\end{array}$ \\
\hline $\begin{array}{l}\text { Biomimetic } \\
\text { Fish } \\
\text { Actuated } \\
\text { by Shape } \\
\text { Memory } \\
\text { Alloy }\end{array}$ & $\begin{array}{l}\text { Develop } \\
\text { Koi's fish } \\
\text { like robot } \\
\text { using SMA to } \\
\text { pectoral and } \\
\text { caudal fin. }\end{array}$ & & $\begin{array}{l}\text { Shape } \\
\text { Memory } \\
\text { Allow link } \\
\text { together } \\
\text { with spring } \\
\text { pulley. }\end{array}$ \\
\hline $\begin{array}{l}\text { A micro- } \\
\text { robot fish } \\
\text { with } \\
\text { embedded } \\
\text { SMA wire }\end{array}$ & $\begin{array}{l}\text { To develop } \\
\text { and study the } \\
\text { robot } \\
\text { propulsion } \\
\text { using SMA. }\end{array}$ & $\underset{\sim \text { lnoty }}{\longrightarrow}$ & $\begin{array}{l}\text { Shape } \\
\text { memory } \\
\text { alloy and } \\
\text { power by } \\
\text { battery. }\end{array}$ \\
\hline
\end{tabular}

\begin{tabular}{|c|c|c|c|}
\hline $\begin{array}{l}\text { actuated } \\
\text { flexible } \\
\text { biomimetic } \\
\text { fin }\end{array}$ & $\begin{array}{l}\text { The result to } \\
\text { identify } \\
\text { whether robot } \\
\text { can swim and } \\
\text { turning using } \\
\text { this method. }\end{array}$ & & \\
\hline $\begin{array}{l}\text { Monolithic } \\
\text { IPMC Fins } \\
\text { for } \\
\text { Propulsion } \\
\text { and } \\
\text { Maneuvering } \\
\text { in } \\
\text { Bioinspired } \\
\text { Underwater } \\
\text { Robotic }\end{array}$ & $\begin{array}{l}\text { To develop } \\
\text { IPMC fins } \\
\text { that can } \\
\text { provide novel } \\
\text { and efficient } \\
\text { propulsion. }\end{array}$ & & $\begin{array}{l}\text { Monolithic } \\
\text { platinum } \\
\text { gold Ionic } \\
\text { polymer- } \\
\text { metal } \\
\text { composite }\end{array}$ \\
\hline $\begin{array}{l}\text { Bio-inspired } \\
\text { robotic } \\
\text { manta ray } \\
\text { powered by } \\
\text { ionic } \\
\text { polymer- } \\
\text { metal } \\
\text { composite } \\
\text { artificial } \\
\text { muscles }\end{array}$ & $\begin{array}{l}\text { To improvise } \\
\text { bio-inspired } \\
\text { robotics } \\
\text { manta ray } \\
\text { propeller } \\
\text { using } \\
\text { artificial } \\
\text { pectoral fins. }\end{array}$ & 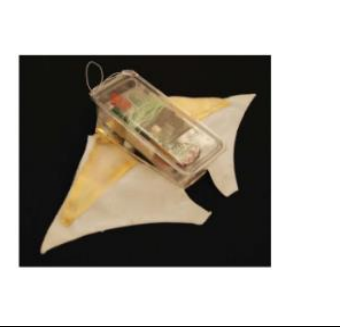 & $\begin{array}{l}\text { Ionic } \\
\text { polymer- } \\
\text { metal } \\
\text { composite } \\
\text { with thin } \\
\text { membrane } \\
\text { of poly- } \\
\text { dimethyl } \\
\text { siloxane } \\
\text { (PDMS) }\end{array}$ \\
\hline $\begin{array}{l}\text { A Bending } \\
\text { Pneumatic } \\
\text { Rubber } \\
\text { Actuator } \\
\text { Realizing } \\
\text { Soft-bodied } \\
\text { Manta } \\
\text { Swimming } \\
\text { Robot }\end{array}$ & $\begin{array}{l}\text { To introduce } \\
\text { modern } \\
\text { design and } \\
\text { prototype for } \\
\text { pneumatic } \\
\text { rubber } \\
\text { actuator for } \\
\text { soft-bodied } \\
\text { manta ray. }\end{array}$ & 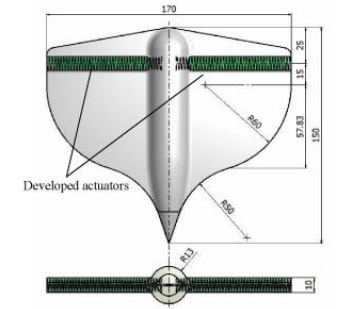 & $\begin{array}{l}\text { Pneumatic } \\
\text { soft actuator }\end{array}$ \\
\hline $\begin{array}{l}\text { Analysis of } \\
\text { the Effect } \\
\text { Waveform } \\
\text { Parameters } \\
\text { have on } \\
\text { Stingray } \\
\text { Surface } \\
\text { Velocity }\end{array}$ & $\begin{array}{l}\text { To analyze } \\
\text { and produce } \\
\text { numerical } \\
\text { model for } \\
\text { baseline oof } \\
\text { robotic } \\
\text { stingray }\end{array}$ & & $\begin{array}{l}\text { Servo } \\
\text { motor }\end{array}$ \\
\hline $\begin{array}{l}\text { Design and } \\
\text { Preliminary } \\
\text { Evaluation } \\
\text { of a } \\
\text { Biomimetic } \\
\text { Underwater } \\
\text { Robot } \\
\text { with } \\
\text { Undulating } \\
\text { Fin } \\
\text { Propulsion }\end{array}$ & $\begin{array}{l}\text { To build a } \\
\text { prototype of } \\
\text { underwater } \\
\text { robot with } \\
\text { undulation } \\
\text { fins } \\
\text { propulsion. }\end{array}$ & $=$ & $\begin{array}{l}\text { Servo } \\
\text { motor } \\
\text { attach with } \\
\text { thin layer of } \\
\text { membrane }\end{array}$ \\
\hline $\begin{array}{l}\text { Fast-moving } \\
\text { soft } \\
\text { electronic } \\
\text { fish }\end{array}$ & $\begin{array}{l}\text { To build } \\
\text { robot using } \\
\text { Dielectric } \\
\text { Elastomer } \\
\text { (DE) soft } \\
\text { actuator. }\end{array}$ & & $\begin{array}{l}\text { Soft } \\
\text { actuator }\end{array}$ \\
\hline $\begin{array}{l}\text { Stingray- } \\
\text { inspired } \\
\text { robot } \\
\text { with simply } \\
\text { actuated } \\
\text { intermediate } \\
\text { motion }\end{array}$ & $\begin{array}{l}\text { To create an } \\
\text { underwater } \\
\text { swimming } \\
\text { robot that } \\
\text { have same } \\
\text { propulsion } \\
\text { method as } \\
\text { dasyatis } \\
\text { americana } \\
\text { stingray }\end{array}$ & & $\begin{array}{l}\text { Servo } \\
\text { motor }\end{array}$ \\
\hline
\end{tabular}




\section{HYBRID PROPULSION}

Hybrid propulsions is a combination of two or more smart materials as a propulsive method for the robot [48,49]. Harbin Engineering University and Kagawa University develop jellyfish like robot by using SMA and IPMC. This method does produce propulsive force by bending both smart actuators to produce propulsive force by bending and shrinking $[50,51]$.

Guo S. et al. also develop a jellyfish like robot using hybrid method of IPMC and SMA with rubber materials as a body. With highest frequency of $0.6 \mathrm{~Hz}$, it produces $6 \mathrm{~mm} / \mathrm{s}$ speed. Fig. 14 shows the structure of the robot. Lead wires use to produce applied voltage to SMA and IPMC. This robot consists of four legs made of IPMC while SMA attach to the body to produce shrinking to mimic the jellyfish.

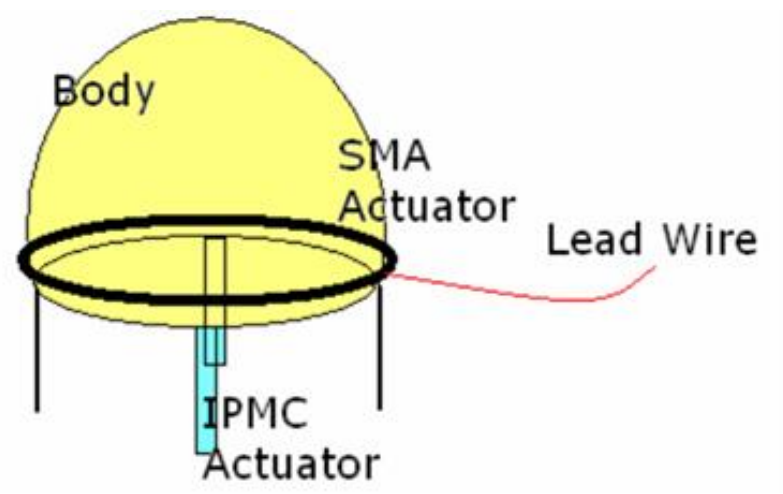

Fig. 14. Structure of the Robot. (Adapted from Guo S. et al.).

\section{MODELLING AND CONTROL OF ROBOTIC FISH}

To control, maneuver and actuate the robot fish, controller is part of the important component to build. Controller system is used to change of normal existing behavior to achieve the desired wanted from the study or design [52],[57],[58]. Controller system usually connection between microcontroller as processor with sensor or transducer as an input for the process [53]. From papers that been discussed in chapter 5, none of them applied control mechanism in their robot since most of the study focus on propulsion of the smart actuator. The use of control mechanisms can improve the robot's capacity to complete tasks.

T.Salumäe et al. robot used two flow sensors located at nose of the robot to sense incoming flow to maintain balance by using Braintenberg $2 \mathrm{~b}$ controller. Braintenberg $2 \mathrm{~b}$ controller perform rheotaxis to maintain the orientation of the robot [64]. The conclusion from this study concludes that rheotaxis behavior can be achieve by measure flow coming to sensor as feedback.

This paper use Brainternerg $2 \mathrm{~b}$ controller for wheeled and implement into fish robot by comparing pressure on both left and right side of the fish body [54]. The result from testing can be seen in Fig. 15. The red line is actual result which can be seen very noisy, and relation based on equation.

$\theta=f\left(P_{R}-P_{L}\right)$

$f$ is frequency of the robot applied. $P_{R}$ and $P_{L}$ can describe as pressure on both right and left sensor.

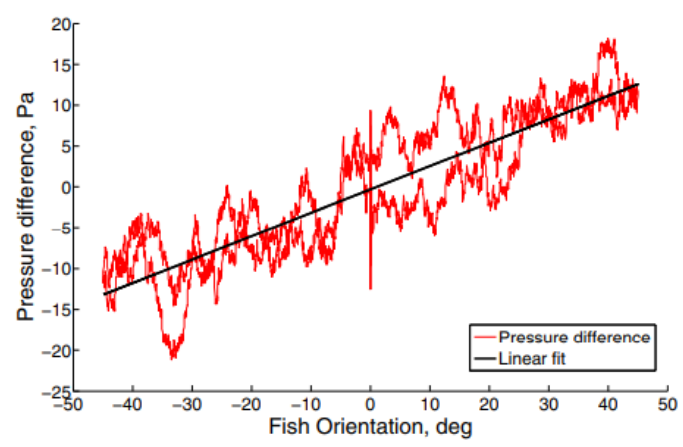

Fig. 15. Pressure difference on the Left and Right Versus the Orientation of the Robot $\theta$.

As the aim of this project to keep angular deviation close to direction of incoming flow. Derived from equation (2), the tail angle offset $\phi_{0}$ can be measure using control law (3) and equation (4) is added to minimize the drift in sensor reading. $K_{\phi}$ and $C_{d}$ here are constant.

$\phi_{0=}\left[0-\left(\mathrm{P}_{\mathrm{R}}-\mathrm{P}_{\mathrm{L}}\right) \mathrm{c}\right] \mathrm{K}_{\phi}$

$\left(\mathrm{P}_{\mathrm{R}}-\mathrm{P}_{\mathrm{L}}\right)_{\mathrm{C}}=\mathrm{C}_{\mathrm{d}} \int\left[0-\left(\mathrm{P}_{\mathrm{R}}-\mathrm{P}_{\mathrm{L}}\right)\right] \mathrm{Dt}+\left(\mathrm{P}_{\mathrm{R}}-\mathrm{P}_{\mathrm{L}}\right)$

To control the tail beat amplitude $(A)$, equation (5) is use. $X_{s p}$ is desired position of the robot and $X_{p v}$ is actual postion of the robot. $K_{A}$ is choosen to be constant.

$\mathrm{A}=\left(\mathrm{X}_{\mathrm{sp}}-\mathrm{X}_{\mathrm{pv}}\right) \mathrm{K}_{\mathrm{A}}$

Ming W. et al. use Central pattern Generator (CPG) as controller to control robotic fish. CPG can be said as all essential or basic movement that require repetitive action of specific muscle [65],[66]. Data from CPG controller is feed to Back Propagation Neural Network (BPNN) to optimize. The design use three separate servomotor joint together to react. BPNN prediction method able to provide optimize motion control for robotic fish swimming [55].

The proportional - integral - derivative (PID) controller is one of the most popular and widely used in the process industry due to its simplicity, wide applicability, and robustness. [68]. Su Si Yuan, et al. used PID controller to perform the steady swim of the fish robot by combining with Kalman filter. Kalman filtering can minimize the movement error and improve movement accuracy to get shortest time to the target based on the variable feed [61]. Fig. 16 shows PID algorithm combining with Kalman filter. According to the findings of this study, combining PID control and the Kalman filter results in faster reaction, better stability, and higher accuracy [56].

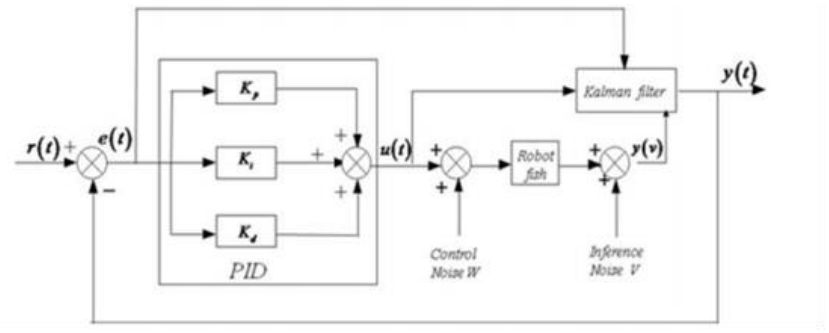

Fig. 16. PID Flowchart Algorithm (Retrieve from Su Si Yuan et al.) 
Kalman filter give five basic formulas.

$$
\begin{aligned}
& \mathrm{X}(\mathrm{k} \mid \mathrm{k}-1)=\mathrm{A} \times \mathrm{X}(\mathrm{k}-1 \mid \mathrm{k}-1)+\mathrm{B} \times \mathrm{U}(\mathrm{k}) \\
& \mathrm{P}(\mathrm{k} \mid \mathrm{k}-1)=\mathrm{A} \times \mathrm{P}(\mathrm{k}-1 \mid \mathrm{k}-1) \mathrm{A}^{\mathrm{T}}+\mathrm{Q} \\
& X(k \mid k)=X(k \mid k-1) K g(k)(Z(k)-H \times X(k \mid k-1)) \\
& K g(k)=\left(P(k \mid k-1) H^{T}\left(H \times P(k \mid k-1) H^{T}+R\right)^{-1}\right. \\
& P(k \mid k)=(1-K g(k) \times H) P(k \mid k-1)
\end{aligned}
$$

$X(k \mid K-1)$ is the prediction of last state. $X(k-1 \mid k-1)$ is the optimal result of last state. $P(k \mid k-1)$ is $X(k \mid k-1)$ prior error, $P$ $(k-1 \mid k-1)$ is $X(k-1 \mid k-1)$ posterior error. $K g$ is the matrix gain and $R$ is system measurement of noise covariance matrix. Based on result achieve by the writer, PID control with Kalman filter may be look deeper to have better understanding and to implement into robot control.

\section{CONCLUSION}

The development of underwater fish robotics is one of the challenging research areas to improve underwater technology [28]. A comprehensive review on biomimetic underwater robots in this paper is reviewed based on their actuators and swimming modes. The ability of a robot to mimic wildlife can help improve the robot such propulsion and maneuverability [63]. Right propulsion materials have shown improvement in building the robot. Each material has its own advantages and disadvantage. It can be understood materials use for actuator has different result and can be applied for different propulsion mode. However, smart materials still slower compared the robot with engine or pump. As for writer, the application of soft actuator shows promising future since its newer technology. Soft actuators use simple implementation to operate. It is understandable that the designed robot must properly mimic the real fish to achieve it desires and to sustain the robot from damaging the aquatic life.

As the fish can adapt to vary environment, robot is manmade machine and lack of this ability. The robot must be equipped with smart technology to face all probable causes by taking proper measurement. As the current research shows promising result, there are still rooms for improvement for underwater robot to work better. This propulsion method with smart actuator can be considered still a testing stage where significant improvement can be made for each smart actuator. Future researcher also may come out with new propulsion alternative which may work better compared to current option. Researcher also may focus on control system and robot design to improve the fish robot itself.

For the robot design, design from the preliminary result show a good result. Depend on reference fish, the design and be both MPF and BCF swimming mode fish. The main idea to be considered during build is the reference fish since it will impact the result. Some fish can swim good in deep water and some fish only good with shallow water. Same goes the water condition with flow since most of the current study do testing in lab, aquarium, or pool. The result may different when put into sea or river or wildlife environment. For further study, it is recommended the testing is done in river or water with flow to study the result.
With the popular demand of underwater robot from various party, researcher technically should improve the current robot to meet with the demand. With the market around 7 million US dollar, it shows that the underwater robot is bigger market than what people seen. Thus, more researcher and study needed to come out with better robot to perform specific task with smart technology.

As the paper initially study to help writer on understanding about biomimetic underwater robot and smart actuator use, this paper also hope can be help for further researcher to understand in developing underwater robot and biomimetic robot.

\section{ACKNOWLEDGMENT}

The authors gratefully acknowledge to the Ministry of Higher Education (MoHE) Malaysia for financial supports given under the Fundamental Research Grant Scheme (FRGS/1/2019/TK04/UNIKL/02/11).

\section{REFERENCES}

[1] G. Eason, Razif Muhammad, Mohd Faudzi, Ahmad Athif, Mohd Nordin, Ili Najaa Aimi, Natarajan, Elango,Yaakob, Omar. A Review on Development of Robotic Fish, (2014), Vol. 1. Pp. 12-22.

[2] Chu, WS., Lee, KT., Song, SH., et al. Review of biomimetic underwater robots using smart actuator. Int. J. Precis. Eng. Manuf.13, (2012).

[3] M. Aminur R B, B. Hemakumar and M. P. R Prasad. Robotic Fish Locomotion \& Propulsion in Marine Environment: A Survey, 2018. 2nd International Conference on Power, Energy and Environment: Towards Smart Technology (ICEPE), pp. 1-6,

[4] Feilich, Kara \& Lauder, George. Passive mechanical models of fish caudal fins: Effects of shape and stiffness on self-propulsion. Bioinspiration \& biomimetics. (2015).

[5] Neely, Lincoln, Gaiennie, Jack, Noble, Nick, Erickson, Jon. Stingrayinspired robot with simply actuated intermediate motion, 2016.

[6] Robert Bogue. Underwater robots: a review of technologies and applications, 2015, Industrial Robot: An International Journal, Vol. 42 Iss 3.

[7] Yinghao Wu, Xuxiang Ta, Ruichao Xiao, Yaoguang Wei, Dong An, Daoliang Li. Survey of underwater robot positioning navigation, Applied Ocean Research, 2019, Volume 90.

[8] Shi, L. Guo, S.; Li, M.; Mao, S.; Xiao, N.; Gao, B.; Song, Z.; Asaka, K. A Novel Soft Biomimetic Microrobot with Two Motion Attitudes. Sensors 2012, 12, 16732-16758.

[9] Amit Shukla, Hamad Karki. Application of robotics in offshore oil and gas industry- A review Part II, Robotics and Autonomous Systems, Volume 75, Part B,2016, Pages 508-524.

[10] Jianhui He, Yonghua Zhang. Development and motion testing of a robotic ray. 2015. Journal of robotic, Vol. 2015.

[11] Sfakiotakis, D. M. Lane and J. B. C. Davies. Review of fish swimming modes for aquatic locomotion.1999. IEEE Journal of Oceanic Engineering, vol. 24, no. 2, pp. 237-252.

[12] Smits, A. Undulatory and oscillatory swimming. (2019). Journal of Fluid Mechanics, 874, P1.

[13] Duraisamy, P., Kumar Sidharthan, R., Nagarajan Santhanakrishnan, M. Design, Modeling, and Control of Biomimetic Fish Robot: A Review. (2019). J Bionic Eng 16, 967-993.

[14] Pichet Suebsaiprom, Chun-Liang Lin, Maneuverability modeling and trajectory tracking for fish robot, Control Engineering Practice, ,2015, Volume 45, Pages 22-36, ISSN 0967-0661.

[15] P. ValdiviaAlvarado, K. Youcef-Toumi. Performance of Machines with Flexible Bodies Designed for Biomimetic Locomotion in Liquid Environments, 2005. IEEE International Conference on Robotics and Automation, 2005, pp. 3324-3329.

[16] S. B. Behbahani and X. Tan. Design and Modeling of Flexible Passive Rowing Joint for Robotic Fish Pectoral Fins. 2016. IEEE Transactions on Robotics, vol. 32, no. 5, pp. 1119-1132. 
[17] S. Zhang, Y. Qian, P. Liao, F. Qin and J. Yang. Design and Control of an Agile Robotic Fish with Integrative Biomimetic Mechanisms. 2016. IEEE/ASME Transactions on Mechatronics, vol. 21, no. 4, pp. 18461857.

[18] Riccio, A.; Napolitano, C.; Sellitto, A.; Acanfora, V.; Zarrelli, M. Development of a Combined Micro-Macro Mechanics Analytical Approach to Design Shape Memory Alloy Spring-Based Actuators and Its Experimental Validation. Sensors 2021, 21, 5506.

[19] K. Suzumori, S. Endo, T. Kanda, N. Kato and H. Suzuki. A Bending Pneumatic Rubber Actuator Realizing Soft-bodied Manta Swimming Robot.2007. Proceedings 2007 IEEE International Conference on Robotics and Automation, 2007, pp. 4975-4980.

[20] J. J. Hubbard, M. Fleming, V. Palmre, D. Pugal, K. J. Kim and K. K. Leang. Monolithic IPMC Fins for Propulsion and Maneuvering in Bioinspired Underwater Robotics. 2014. in IEEE Journal of Oceanic Engineering, vol. 39, no. 3, pp. 540-551, July 2014.

[21] Huang, P. H., \& Wang, J. A New Design of Underwater Robot Fish System Using Shape Memory Alloy. Applied Mechanics and Materials. (2012). Pp. 187, 260-266.

[22] Li T, Li G, Liang Y, Cheng T, Dai J, Yang X, Liu B, Zeng Z, Huang Z, Luo Y, Xie T, Yang W. Fast-moving soft electronic fish. Sci Adv. 2017.

[23] M. Sfakiotakis, D. M. Lane and J. B. C. Davies. Review of fish swimming modes for aquatic locomotion. 1999. in IEEE Journal of Oceanic Engineering, vol. 24, no. 2, pp. 237-252, April 1999.

[24] Jian-Xin Xu, Qinyuan Ren, Wenchao Gao and Xue-Lei Niu. Mimicry of fish swimming patterns in a robotic fish. 2012. IEEE International Symposium on Industrial Electronics, 2012, pp. 1274-1279.

[25] X. Niu, J. Xu, Q. Ren and Q. Wang. Locomotion Learning for an Anguilliform Robotic Fish Using Central Pattern Generator Approach. 2014. IEEE Transactions on Industrial Electronics, vol. 61, no. 9, pp. 4780-4787, Sept. 2014.

[26] Song, Sung-Hyuk, Lee Hyeok, Lee Jonggu, \& Lee, Jang-Yeob, Cho, Maenghyo, Ahn, Sung-Hoon. Design and analysis of a smart soft composite structure for various modes of actuation. (2016). Composites Part B: Engineering. 95.

[27] D. Zhang, K. H. Low, H. Xie and L. Shen. Advances and Trends of Bionic Underwater Propulsors.2009. WRI Global Congress on Intelligent Systems, 2009, pp. 13-19.

[28] Curet, Oscar, Patankar, Neelesh, Lauder, George, Maciver, Malcolm. Mechanical properties of a bio-inspired robotic knifefish with an undulatory propulsor. (2011). Bioinspiration \& biomimetics.

[29] Hirata K. Development of experimental fish robot. Proc. of Japan Society for Design Engineering, Tohoku Branch.

[30] Deepak Trivedi, Christopher D. Rahn, William M. Kier \& Ian D. Walker. Soft robotics: Biological inspiration, state of the art, and future research. (2008). Applied Bionics and Biomechanics.

[31] Blake, R. W. REVIEW PAPER Fish functional design and swimming performance (2004).

[32] X. Niu, J. Xu, Q. Ren, Q. Wang. Locomotion Learning for an Anguilliform Robotic Fish Using Central Pattern Generator Approach. 2014. IEEE Transactions on Industrial Electronics, vol. 61, no. 9, pp. 4780-4787, Sept. 2014.

[33] Pichet Suebsaiprom, Chun-Liang Lin, Anumat Engkaninan. Undulatory locomotion and effective propulsion for fish-inspired robot.

[34] J. Finkbeiner, J. Ahmad, W. Santosa, G. Y. Xu and J. Xiao, "Biomimetic fish actuated by shape memory alloy," 2011 6th IEEE Conference on Industrial Electronics and Applications, 2011, pp. 2139-2144, Doi: 10.1109/ICIEA.2011.5975945.

[35] Z. Wang, Y. Wang, J. Li and G. Hang, "A micro biomimetic manta ray robot fish actuated by SMA," 2009 IEEE International Conference on Robotics and Biomimetics (ROBIO), 2009, pp. 1809-1813, Doi: 10.1109/ROBIO.2009.5420423.

[36] Zhenlong Wang, Guanrong Hang, Jian Li, Yangwei Wang, Kai Xiao. A micro-robot fish with embedded SMA wire actuated flexible biomimetic fin. (2008).

[37] Xiufen Ye, Yudong Su and Shuxiang Guo, "A centimeter-scale autonomous robotic fish actuated by IPMC actuator," 2007 IEEE
International Conference on Robotics and Biomimetics (ROBIO), 2007, pp. 262-267.

[38] Zheng Chen, Tae I. Um \& Hilary Bart-Smith (2012) Bio-inspired robotic manta ray powered by ionic polymer-metal composite artificial muscles, International Journal of Smart and Nano Materials/.

[39] Chen, Zheng \& Um, Tae \& Bart-Smith, Hilary. (2011). Ionic PolymerMetal Composite Enabled Robotic Manta Ray. Proceedings of SPIE The International Society for Optical Engineering.

[40] Hao M, Wang Y, Zhu Z, He Q, Zhu D and Luo M. A compact review of IPMC as soft actuator and sensor: current trends, challenges and potential solutions from our recent works. (2019).

[41] Nowell, Jordan \& Connor, Jack \& Joordens, Matthew \& Champion, Benjamin. (2018). Analysis of the Effect Waveform Parameters have on Stingray Surface Velocity.

[42] Lei Liu et al 2020 IOP Conf. Ser.: Mater. Sci. Eng. 790012160.

[43] Ying He, Dao Bo Wang and Zain Anwar Ali. A review of different designs and control models of remotely operated underwater vehicle. (2020).

[44] Marras Stefano and Porfiri Maurizio. 2012.Fish and robots swimming together: attraction towards the robot demands biomimetic locomotionJ. R. Soc. Interface.

[45] Riccio, A.; Napolitano, C.; Sellitto, A.; Acanfora, V.; Zarrelli, M. Development of a Combined Micro-Macro Mechanics Analytical Approach to Design Shape Memory Alloy Spring-Based Actuators and Its Experimental Validation. Sensors 2021, 21, 5506.

[46] Mohd Aliff, Ahmad Raziq Mirza, Mohd Ismail and Nor Samsiah, "Development of a Low-Cost Bio-Inspired Swimming Robot (SRob) with IoT" International Journal of Advanced Computer Science and Applications (IJACSA), 12(7), 2021.

[47] T. V. Truong, V. K. Viswanathan, V. S. Joseph and P. V. y. Alvarado, -Design and Characterization of a Fully Autonomous Under-Actuated Soft Batoid-like Robot, 2019 IEEE/RSJ International Conference on Intelligent Robots and Systems (IROS), 2019, pp. 5826-5831.

[48] C. M. Chew, Q. Y. Lim, and K. S. Yeo, -Development of propulsion mechanism for Robot Manta Ray, in Robotics and Biomimetics (ROBIO), 2015 IEEE International Conference on, pp. 1918-1923.

[49] Y. Yang, X. Ye and S. Guo, "A New Type of Jellyfish-Like Microrobot," 2007 IEEE International Conference on Integration Technology, 2007, pp. 673-678.

[50] S. Guo, L. Shi, X. Ye and L. Li, "A New Jellyfish Type of Underwater Microrobot," 2007 International Conference on Mechatronics and Automation, 2007, pp. 509-514.

[51] B. Tang, L. Jiang and R. Li, "Bionic Robot Jellyfish Based on MultiLink Mechanism," 2020 International Wireless Communications and Mobile Computing (IWCMC), 2020, pp. 649-652.

[52] Canete, J. \& Galindo, Cipriano \& Moral, Inmaculada. (2011). Introduction to Control Systems. 10.1007/978-3-642-20230-8_5.

[53] T. Salumäe, I. Rañó, O. Akanyeti and M. Kruusmaa, "Against the flow: A Braitenberg controller for a fish robot," 2012 IEEE International Conference on Robotics and Automation, 2012, pp. 4210-4215.

[54] Wang Ming, Yu Junzhi, TanMin and Yang Qinghai, "Back-Propagation Neural Network based predictive control for biomimetic robotic fish," 2008 27th Chinese Control Conference, 2008, pp. 430-434.

[55] Su, Si Yuan, et al. "Robotic Fish's Movement Based on Kalman Filter and PID Control." Applied Mechanics and Materials, vol. 568-570, Trans Tech Publications, Ltd., June 2014, pp. 1059-1062. Crossref, Doi: 10.4028/www.scientific.net/amm.568-570.1059.

[56] Lei Liu, et al. 2020. Design and Premilinary Evaluation of a Biomimetic Underwater Robot with Undulating Fin Propulsion. IOP Conf. Ser.: Mater. Sci. Eng.

[57] Shi, Q., Ishii, H., Sugahara, Y., Takanishi, A., Huang, Q., \& Fukuda, T. (2015). Design and Control of a Biomimetic Robotic Rat for Interaction with Laboratory Rats. IEEE/ASME Transactions on Mechatronics, 20(4), 1832-1842.

[58] Lauder, G. V., \& Santo, V. D. (2015). Swimming Mechanics and Energetics of Elasmobranch Fishes. Fish Physiology Physiology of Elasmobranch Fishes: Structure and Interaction with Environment, 219253. 
[59] Yamakita, M., Kamamichi, N., Luo, Z. W., \& Asaka, K. (2016). Robotic Application of IPMC Actuators with Redoping Capability. Electroactive Polymers for Robotic Applications, 199-225.

[60] Kiebert, L., \& Joordens, M. (2016). Autonomous robotic fish for a swarm environment. 2016 11th System of Systems Engineering Conference (SoSE).

[61] Younghoo K and Hyochong B. (2019). Introduction to Kalman Filter and Its Applications. DOI 10.5772/intechopen.80600.

[62] G. Li, Y. Deng, O. L. Osen, S. Bi, and H. Zhang, -A bio-inspired swimming robot for marine aquaculture applications: From conceptdesign to simulation, $\|$ OCEANS 2016 - Shanghai, 2016, pp. 1-7.

[63] Shi, L., Guo, S., and Asaka, K., "A novel multifunctional underwater microrobot," 2010 IEEE International Conference on Robotics and Biomimetics (ROBIO) pp. 873-878, 2010.
[64] Pan, X., Li, L., Chen, S., \& Xie, G. (2015). An effective tracking control for robotic fish: Implementation and application. 2015 34th Chinese Control Conference (CCC). doi:10.1109/chicc.2015.7260598.

[65] Bucher, D., haspel, G., Golowasch, J., \& Nadim, f> (2015). Central Pattern Generators. DOI 10.1002/9780470015902.a0000032.pub2.

[66] Marder, E., and Bucher D.,. 2001. Central pattern generators and the control of rhythmic movements, Current Biology, https://doi.org/10.1016/S0960-9822(01)00581-4.

[67] Degeratu, S., Bîzdoaca, N.G., Manolea, G., Diaconu, I., Petrisor, A., \& Degeratu, V. (2008). On the design of a shape memory alloy spring actuator using thermal analysis. WSEAS TRANSACTIONS on SYSTEMS archive, 7, 1006-1015.

[68] Navid Razmjooyand Mehdi Ramezani. (2014). Using Quantum Gates to design a PID Controller for Nano robots. International Research. Journal of Applied and Basic Sciences, 8(12), 2354-2359. 